SUGGISTIONS AS TO THE CAUSES FOR COLOR CHANGES

Ortho-tolidine is an organic compound of the formula $\mathrm{C}_{14} \mathrm{H}_{16} \mathrm{~N}_{2}{ }^{1} \quad$ It is a homolog of benzidine and is a powder melting at $129^{\circ} \mathrm{C}$. It may be prepared from o-nitrotoluene by reduction with zinc dust and sodium hydroxide. The resulting hydrazo-toluene is converted into the o-tolidine by boiling with hydrochloric acid. It may be purified in a manner similar to that of benzidine. Its structural formula may be written as at (I):<smiles>CC1CCC(C2CCCCC2)CC1</smiles><smiles>CC1CCC(C2CCNC(C)C2)CC1</smiles>

(2)

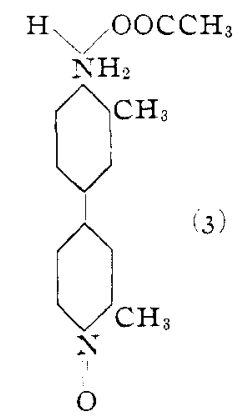

It is a $p$-2-diamido-m-2-dimethyldiphenyl compound. and probably produces dyes of the same general type as those derived from benzidine. Oxidation of $o$-tolidine probably produces a nitroso compound of formula (2): this compound is probably blue in color. Salts of o-tolidine upon oxidation produce a yellow dye, a possible formula for the acetic acic salt being $(3)$.

The green color produced by the action of the chlorine on the acetic acid solution of o-tolidine is probably a mixture of the blue compound (2) and the yellow compound (3). In the hydrochloric acid solution of o-tolidine, $\mathrm{HCl}$ is merely substituted for $\mathrm{HOOCCH}_{3}$. The slight dissociation of acetic acid and the hydrolysis of the acetate perhaps account for the slow formation of the yellow dye in the acetic acid solution, while the large dissociation of hydrochloric acid might be the reason for the rapid development of the yellow color in the hydrochloric acid solution.

The red color and red precipitate produced by large amounts of chlorine may be a substitution product of the nitroso compound resulting from the complete oxidation of all the o-tolidine present.

Aniline treated with a solution of bleaching powder produces certain color reactions, but it requires a consiclerable amount of chlorine for their development. Similarly ortho-toluidine forms colored solutions with chlorine. which are likewise slowly developed, although somewhat more rapidly than in the case of aniline. As has been previously noted benzidine readily produces colored solutions with chlorine. similar to those formed with o-tolidine. Its sensitiveness to chlorine is much greater than is that of aniline or o-toluidine but somewhat less than that of $o$-tolidine.

The colors produced by a solution of bleaching powder in gradually increasing quantities with neutral and with acid alcoholic solutions of aniline, $a$-toluidine, benzidine and o-tolidine are shown in the following table:

1 Beilstein, 3rd edition, Vol. 4, page 980.

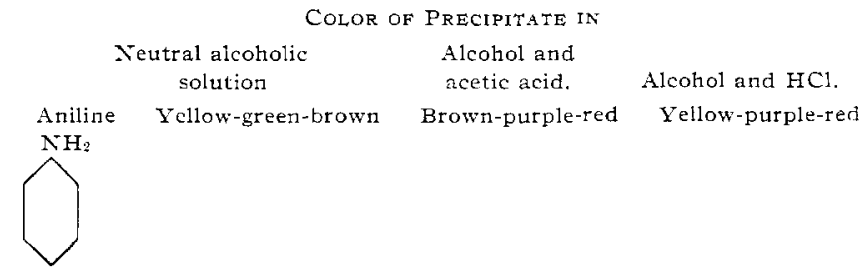

o-Toluidine Yellow-orange-brown Purple-blue-red Purple-red

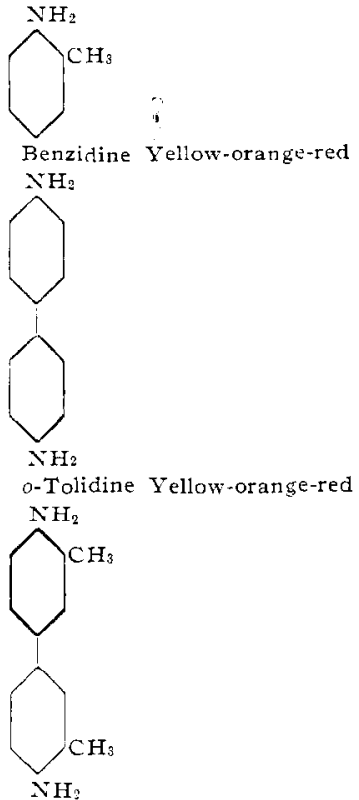

Green-orange-red Yellow-orange-red

Green-orange-red Yellow-orange-red

A blue color reaction produced by the action of hypochlorites on methyl-aniline and ethyl-aniline has been recently reported by Leech. ${ }^{1}$ He suggests that the blue dye, possibly a member of the "indo" series of dyes, results from the oxidation of the methyl or ethyl group. It seems to the authors that in the case of $o$-toluidine and o-tolidine that the dyes are produced as a result of the oxidation of the amido group, and not the methyl group, since in aniline and benzidine, having no methyl groups, similar dyes are formed by the action of hypochlorites.

Cincingati filtration Peant Cincinnati, Ohio

\section{THE QUANTITATIVE ESTIMATION OF GLIADIN IN FLOUR AND GLUTEN}

By Geo. A. Olson

Received July 26, 1913

Since Einhof ${ }^{2}$ separated alcohol-soluble proteins from wheat, rye and barley, much interesting research work has been done on prolamines. It was not, however, until Osborne and Voorhees ${ }^{3}$ presented a study on the proteins of the wheat kernel that a clear understanding as to the nature of vegetable proteins was established. Of particular interest was the research on gliadin, the prolamine of wheat. It has been further believed that the proportion of gliadin to glutenin determines the quality of the gluten which in turn

1 "A Color Reaction of Hypochlorites with Methyl-Aniline and Ethy:Aniline," by Paul N. Leech, Jour. Am. Chem. Soc. 36, No. 8 (August, 1913 ). 'See "The Proteins of the Wheat Kernel and Vegetable Proteins," by Thomas B. Osborne. Also Trans, of the Canadian Institute, 7, 1903, by George G. Nasmith.

${ }^{3}$ Amer. Chem. J., 15, 392 (1893). 
determines the quality of a flour for bread-making purposes. ${ }^{1}$

Following Millon's ${ }^{2}$ work on the quantity of gluten contained in different kinds of wheat, another series of investigations bearing on the relationship of the gluten to the baking qualities of flour was commenced. Heinrichs ${ }^{3}$ failed to establish any relationship between the gluten and baking quality, but Fleurent $t^{4}$ was led to believe that the alcohol-soluble portion of the gluten, rather than gluten, determines the baking qualities of flour. The method adopted by Fleurent for the extraction of gliadin cannot be said to be satisfactory since the diluted alcohol contains potassium hydroxide and potassium hydroxide like sodium hydroxide is a solvent for glutenin as well as for gliadin.

Based upon Osborne's and Voorhees' work, Teller worked out a method which he used for the estimation of gliadin in wheat at different periods of growth. $\mathrm{He}$, and subsequently Chamberlain ${ }^{6}$ and others, observed that a part of the alcohol-soluble nitrogen was extracted by salt solution. The writer in his studies on the nitrogen components of wheat flour has confirmed this work. The fact that the quantitative methods which we follow for the estimation of proteins in wheat flour are far from satisfactory, led the writer to carry out a series of experiments, some of the results of which are recorded below.

The strength of alcohol most suitable for the extraction of gliadin from flour, or gluten, has never been determined. It is known that above certain strengths of alcohol little or no gliadin can be extracted, while below this limit all the gliadin can be extracted, provided enough solvent is used. Teller ${ }^{1}$ studied the solubility of proteids in different strengths of alcohol and found that while the quantity of nitrogen extracted increased with the dilution of alcohol until a maximum amount of alcohol-soluble nitrogen products had been extracted, solutions containing from 40 per cent to 60 per cent alcohol gave identical results. From 65 per cent to 95 per cent by volume, the per cent of nitrogen products decreased rapidly. Osborne and Voorhees in their work used an alcohol of $0.90 \mathrm{sp}$. gr. Later $\mathrm{Shutt}^{8}$ and $\mathrm{Humme}{ }^{9}$ observed between the range of 60 per cent to 75 per cent alcohol, by weight, that the nitrogen content of flour soluble in alcohol decreased with the increased strength of alcohol. Between 60 per cent and 86.4 per cent alcohol, by weight, Shutt observed the same order of solubility: with 86.4 per cent alcohol only 0.12 per cent nitrogen; compared with 60 per cent alcohol 0.94 per cent nitrogen was noted. Hoagland, ${ }^{10}$ working with two samples of flour, observed that more nitrogen was extracted with water than with alcohol of strengths ranging from Io to 20 per cent by weight. Increasing the strength to

1 Agr. Gazelte N. S. Wales, Sept., 1896. Jour. Amer. Chem. Soc, 1900, 263. Ibid., 1905, 1068. Compt. rend., 1896, 123, 155.

2 Jour. f. prakt. Chem., Bd. 61, 344 (1854).

${ }_{3}^{3}$ Berichte d. Landw. Versuchs. Rostock, 1894.

- Compt. rend., 1896, 327

5 Ark. Bull. No. 53.

${ }^{6}$ U. S. Dept. of Agr., Bur. of Chem., Butt. No. 81.

7 Ibid., Bull. No. 90.

$\$$ Central Exp. Farm, Ottawa, Can., 1907.

${ }^{9}$ U. S. Dept. of Agr., Bur, of Chem., Buil. No. 105.

10 This Jolrnal, 3, No. 11, 838 .
75 per cent by weight, Hoagland found that alcohol of 40 to 45 per cent by weight extracted as much or more nitrogen products than strengths ranging between 60 to 75 per cent by weight. He believes a 50 per cent alcohol by weight to be the logical strength to use. It should be remembered that Osborne and Voorhees separated the gliadin or its nitrogen from the alcohol-soluble nitrogen. The fact that larger quantities of nitrogen-carrying bodies are extracted with weaker alcohols does not prove that larger quantities of gliadin are extracted, yet nitrogen determinations are made and it is assumed that such is the case.

The observations of Kjeldahl, ${ }^{1}$ Mathewson, ${ }^{2}$ and Osborne and Harris ${ }^{3}$ showed the specific rotation of gliadin, $[\boldsymbol{\alpha}]_{D}-9_{2}$ to be uniformly constant. Snyder 4 introduced a method for the estimation of gliadin which proved unsatisfactory in the hands of others. Thatcher ${ }^{5}$ was unable to use the method on soft wheat flours. Shaw and Gaumitz ${ }^{6}$ state in their paper that "the gliadin nitrogen should be corrected for the amide nitrogen present, but for most practical purposes this may be neglected," especially "with old and unsound flours a correction must be made for the soluble amide bodies." Chamberlain also is of the opinion that amide compounds soluble in alcohol are considered as gliadin in the proposed methods.

Greaves, ${ }^{7}$ in his thesis work, with the aid of the polariscope, found that 70 per cent alcohol extracted more nitrogen in smaller quantities of flour than where the same quantity of alcohol acted upon larger quantities of flour. Chamberlain recommended that at least I $00 \mathrm{cc}$. of alcohol per 2 grams of flour should be used. In working with alcohol ranging from 60 per cent to 80 per cent by weight, Greaves obtained the largest amount of nitrogen, with a few exceptions, with 70 per cent alcohol. The highest specific rotation $[\alpha]$ -89.80 was observed with 74 per cent alcohol, and he is of the opinion that this is more nearly true gliadin than gliadin extractions made with other strengths of alcohol.

In studies with hot alcohol compared with cold, Chamberlain ${ }^{8}$ obtained more gliadin nitrogen in cold alcohol than in case of hot alcohol. Leach ${ }^{9}$ recommends $100 \mathrm{cc}$. of 75 per cent hot alcohol per gram of material. Hoagland found that at a temperature of $75^{\circ} \mathrm{C}$, and below the latter temperature, there is practically no temperature effect on the amount of nitrogen extracted. Greaves, employing tightly stoppered pressure flasks, obtained higher results with hot alcohol compared with cold.

In the earlier investigations on gliadin the experimental work was directed towards the preparation of pure gliadin, so that it was possible to properly identify and classify it. In the latter researches, when quantitative methods were cesired, the sum total nitrogen

\footnotetext{
1 Centralbl. Agr. Chem, 25, 197 (1896).

2 Jour. A mer. Chem. Soc, 28, 1482 (1906)

3 Ibid., 24, 844 (1903).

lbid., 26, 263 (1904)

5 Ibid., 29, $910(1907)$.

- Calif Bull., No. 212.

J J. Biol. Chem., 9, 3-4, 271.

Jour. Amer. Chem. Soc., 28, No. 11.

${ }^{9}$ Food Inspection and Analyses, p. 232.
} 
extracted by alcohol has been considered pure gliadin. In literature, there is nothing to show that all of the nitrogen compounds present in the alcohol-soluble is the nitrogen of pure gliadin. There is, on the other hand, some indication that a part at least of the nitrogen products is a part of less complex substances than gliadin, e. g., amides. There is some evidence that substances closely allied to gliadin are present and which O'Brien" believes "closely merge into one another."

The general methods adopted for the separation of gliadin from its solvent have been either to dilute the alcohol and add salt solution or increase the strength of alcohol by adding absolute alcohol. Osborne states that distilling off the alcohol in vacuo causes the settling out of gliadin. This latter method has been made use of by the writer when handling large quantities of material.

But where the quantity of material is small and the exact purity of the material is of secondary importance, the writer has evaporated off the alcohol in the open, thereby causing precipitation or settling out of protein. Owing to the peculiar properties of gliadin and the similar properties of the coagulum it is reasonable to believe that they are one and the same substance. The gliadin, however, is purer than the precipitate due to the fact that it is redissolved and precipitated a number of times. The nitrogen bodies dissolved by the alcohol and not precipitated are nongliadin bodies which from a quantitative point of view are generally included as gliadin nitrogen.

This means of separating the alcohol-soluble nitrogen materials into two groups offers a satisfactory working basis for the estimation of gliadin in flour or gluten. In some respects such a method is similar to the one in vogue for the estimation of casein in milk.

In order to learn whether or no it was possible to make use of the above method for the estimation of gliadin it was necessary to include with it the estimations for the salt-soluble protein substances found in flour.

In the preliminary experiments a series of four flours were selected. These were first extracted with one per cent salt solution $(\mathrm{NaCl})$, followed by treating the insoluble residue with sufficient 95 per cent alcohol to make an alcohol 70 per cent by volume. A direct 70 per cent alcohol separation was also made. Besides this, $50 \mathrm{cc}$. aliquot of the direct alcohol-soluble separation was evaporated to within $5 \mathrm{cc}$, $50 \mathrm{cc}$. of water added, boiled, and then cooled to room temperature. A heavy coagulum or settling out resulted upon the evaporation of the alcohol and increased in amount upon cooling after the boiling.

An aliquot of the I per cent salt-soluble was evaporated to dryness and then extracted with $7 \circ$ per cent alcohol, in order to remove the gliadin which, according to Teller and confirmed by Chamberlain, is appreciably soluble in I per cent salt solution. The residue remaining after the alcohol extraction should be composed largely, if not all, of edestin and leucosin. The alcohol extraction in the dried salt solution should

\footnotetext{
I Annals of Bol., 1895, p. 182.
}

carry with it the coagulable and non-coagulable nitrogen which was removed by the salt solution.

Nitrogen determinations were made by the straight Kjeldahl method in the flour, the direct extraction of the flour with 70 per cent alcohol, the coagulum in this alcohol-soluble, the alcohol-soluble resulting after the extraction of the flour with i per cent salt solution, the salt-soluble extraction and the salt-soluble insoluble in 70 per cent alcohol. The results obtained for the above determinations are recorded in Table $I$.

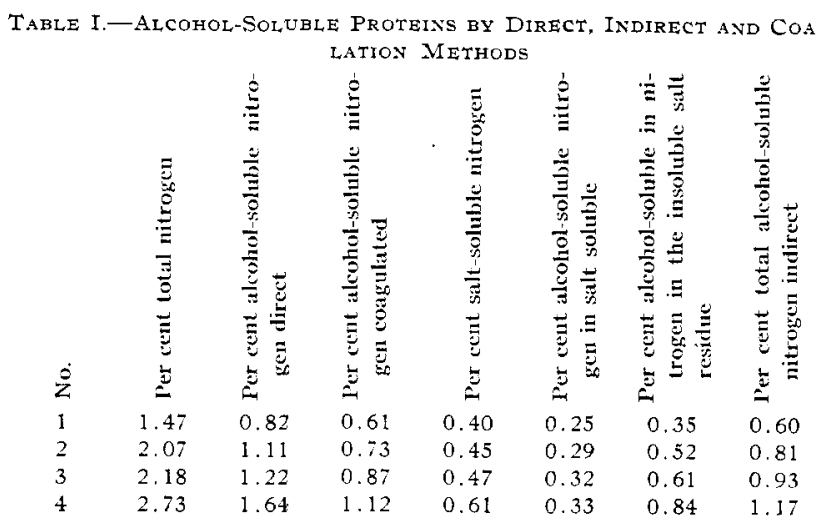

The data given in Table I give results by the direct process of extracting flour for nitrogen-carrying bodies as well as the reverse process. The results obtained are not comparable with each other in the two methods. More than this, the data show that salt extracts a part of the alcohol-soluble nitrogencarrying bodies and 70 per cent alcohol by volume applied directly to a flour removes larger amounts of protein than can be accounted for by the indirect method. The excess amount of alcohol-soluble by the direct method possibly has been altered upon evaporating the salt-soluble and hence is no longer soluble in this strength of alcohol. The data further show that a large part of the alcohol-soluble nitrogen-carrying bodies are coagulated when the alcohol is removed and boiled with water. These results further indicate that a part of the alcohol-soluble nitrogen-carrying bodies is estimated as leucosin and edestin when I per cent salt solution is used. Similar results were obtained by Chamberlain who extracted the flour with alcohol followed by extracting the alcohol residue with a 5 per cent solution of potassium sulfate. The amount of nitrogen-carrying bodies extracted from the alcohol residue as obtained by him was only one-fifth as much as that obtained by the direct extraction of the flour with 5 per cent potassium sulfate.

Perhaps the most interesting results obtained were the remarkably close agreement between the nitrogen in the alcohol-soluble coagulum and that of the alcoholsoluble nitrogen where the flour had first been extracted with I per cent salt solution together with that extracted in the direct salt-soluble. These data add further evidence that alcohol extracts other nitrogenous substances from flour than gliadin and that "gliadin is appreciably soluble in I per cent salt solution." In this series of experiments approximately 72 per cent of the total alcohol-soluble nitrogen is gliadin nitrogen 
based on either the coagulum nitrogen or the alcoholsoluble nitrogen by the indirect method.

Owing to the close agreement in the nitrogen content in the coagulum compared with the nitrogen content in the alcohol-soluble by the indirect method it appears reasonable to the writer that either one of the two methods mentioned here would be satisfactory for the estimation of gliadin nitrogen. The method for the determination of the coagulable nitrogen is the shortest and the better one to follow of the two and as a result the writer has devoted his time to a study of this method.

As has been stated, the strength of alcohol best suited for gliadin estimation has never been fixed. Greaves believes that a 74 per cent alcohol is the proper strength to use in polariscopic estimations, while variable strengths have been suggested in gravimetric estimations. For this reason it is necessary to determine a strength that would be suitable for the work involved.

Two samples of flours were digested with cold 45 , $50,55,60,65,70,75,80$, and 85 per cent alcohol by volume and the nitrogen determined in an aliquot of the alcohol-soluble as well as in the coagulum resulting from another aliquot of the alcohol-soluble. Nitrogen determinations were also made in the phosphotungstic precipitates resulting from the coagulum filtrates. The results for nitrogen in the alcohol-soluble, the coagulum filtrate and the sum of the last two determinations are recorded in Table II of this paper.

Table II-Amount of Coagulable Nitrogen Obtained in Different STRENGTHS OF ALCOHOL

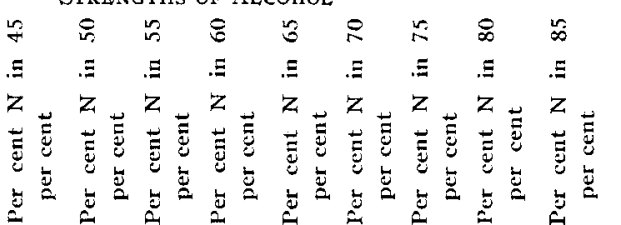

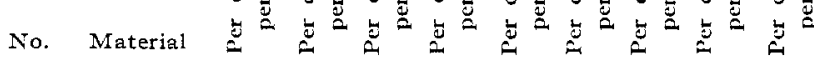

A. Direct.... $\quad \begin{array}{llllllllllll}1.23 & 1.29 & 1.30 & 1.30 & 1.25 & 1.21 & 0.99 & 0.78 & 0.33\end{array}$ $\begin{array}{llllllllllll}\text { Coagulum. } & 0.87 & 0.82 & 0.84 & 0.84 & 0.77 & 0.75 & 0.61 & 0.59 & 0.15\end{array}$ Precipitated

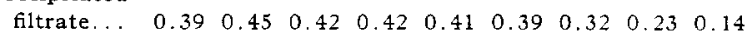
$\begin{array}{llllllllllll}\text { Total....... } & 1.26 & 1.27 & 1.26 & 1.26 & 1.18 & 1.14 & 0.93 & 0.82 & 0.29\end{array}$

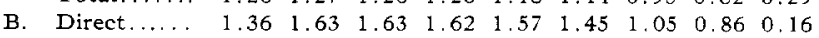

$\begin{array}{lllllllllll}\text { Coagulum. . } & 1.14 & 1.18 \cdot 1.21 & 1.21 & 1.17 & 1.08 & 0.72 & 0.50 & 0.02\end{array}$

Precipitated

$\begin{array}{lllllllllll}\text { filtrate... } & 0.24 & 0.37 & 0.34 & 0.35 & 0.35 & 0.31 & 0.36 & 0.26 & 0.13\end{array}$

$\begin{array}{lllllllllll}\text { Total . . . . } & 1.38 & 1.55 & 1.55 & 1.56 & 1.52 & 1.39 & 1.08 & 0.78 & 0.15\end{array}$

There are several things of interest to be noted in the data given in Table II. The per cent of nitrogen obtained in the coagulum after removing the alcohol runs quite uniformly regardless of strengths of alcohol ranging between 50 per cent to 65 per cent inclusive alcohol by volume. From 70 per cent there is a marked decrease in the per cent of nitrogen until at 85 per cent only about 25 per cent of the total nitrogen in the alcohol-soluble is obtained. The per cent of nitrogen in the phosphotungstic acid precipitated filtrate bears a similar relation. The sum of the per cents of nitrogen in the coagulum and phosphotungstic acid precipitate agree fairly well with the per cents of nitrogen obtained by the direct alcohol extraction.

In regard to the per cents of nitrogen-solubles in different per cents of alcohol it will be noted that the results agree with those observed, first by Teller, and later by other investigators. From these results it appears that a 50 per cent alcohol by volume is satisfactory to use for the estimation of the per cent of nitrogen in the coagulum. The slight variations noted in the totals compared with the results by the direct method are undoubtedly due to analytical error.

The following method was finally adopted for the study of coagulum fraction of the alcohol-soluble. Four grams of flour were digested with $200 \mathrm{cc}$. of 50 per cent alcohol by volume, shaking the entire contents at intervals of five minutes apart during the first two hours, then allowing to stand twenty-four hours followed by fltering clear. Aliquots of $50 \mathrm{cc}$. each were taken from the thoroughly mixed filtrate, evaporated slowly to within $5 \mathrm{cc}$. volume, $50 \mathrm{cc}$. of water added to each and further evaporated at a temperature near to boiling until contents of beakers approximately amounted to $\mathrm{Io} \mathrm{cc}$, repeating $50 \mathrm{cc}$. of water were added and again evaporated down to within $35 \mathrm{cc}$. The beakers were then removed, $25 \mathrm{cc}$. water added, allowed to cool to room temperature $\left(2 I^{\circ}\right)$ and finally filtered. In case of turbid filtrates, the filtrates were repeatedly filtered until clear. The coagulum is difficult to remove in most instances, owing to the sticky nature of this substance, and in such cases the mass was gathered by the use of steel spatula and policeman and transferred to filter paper, occasionally using cold, distilled water to facilitate the transferring and washing of the coagulum. Nitrogen determinations were made according to the Kjeldahl method. The proper corrections for paper and reagents were taken into consideration in all determinations for nitrogen.

The filtrates resulting from the separation of the coagulum were treated with sufficient phosphotungstic acid and nitrogen determined in precipitate and filter paper.

In a series of experiments comprising sixty different flours obtained from different sources, representing different climatic zones in the United States, some of which known as spring or winter wheat patents, others straight, or bakers, some of better baking qualities than others, were subjected to the above mentioned method for the determination of gliadin. The average maximum and minimum results for Table III-Per Cent Nitrogen in Aicohol Fractions

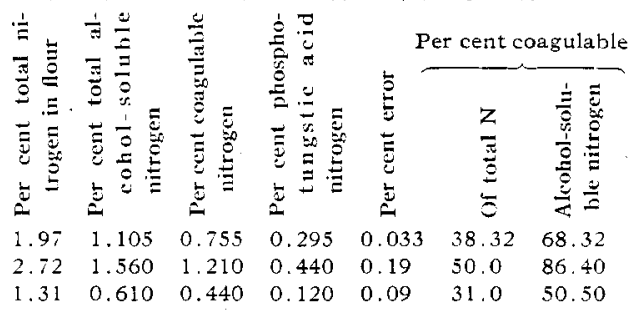

$\begin{array}{llllllll}\text { Average }(60) \ldots . & 1.98 & 1.560 & 1.210 & 0.440 & 0.19 & 50.0 & 86.40\end{array}$

$\begin{array}{llllllll}\text { Minimum..... } 1.31 & 0.610 & 0.440 & 0.120 & 0.09 & 31.0 & 50.50\end{array}$ per cents of total nitrogen in flour, alcohol-soluble nitrogen, coagulable nitrogen in alcohol-soluble and nitrogen in phosphotungstic acid precipitate are recorded in Table III. In addition the per cent of coagulable nitrogen expressed in per cent of total nitrogen in the flour and alcohol-soluble are included. 
According to the results summarized in Table III, it will be noted that the per cent of coagulable nitrogen of total nitrogen in the flour is 38.52 , while the per cent of coagulable of total alcohol-soluble is 68.32 . It is further noted that all of the alcohol-soluble nitrogen is not coagulable nitrogen and that which is not coagulable is precipitated by phosphotungstic acid. If the coagulable nitrogen contains all of the gliadin nitrogen of flour, it will be noted that this nitrogen does not bear any relation to the total alcohol-soluble, nor total nitrogen of the flour.

In connection with this work it was thought desirable to carry out a few comparative tests as to the purity of the coagulum from a nitrogen point of view with the mass obtained in the alcohol-soluble. Four flours from as many different states were selected for this work. The per cent of total solids, per cent of nitrogen in the solids, the per cent coagulum, per cent of nitrogen in coagulum, per cent ash in coagulum, and per cent of sugar in filtrate resulting from the separation of the coagulum are recorded in Table IV.

\begin{tabular}{|c|c|c|c|c|c|c|}
\hline \multirow[t]{3}{*}{ TABLE } & \multicolumn{3}{|c|}{$\begin{array}{r}\text { AICOHOL-SOLUBLE } \\
\text { COAGULUM }\end{array}$} & \multicolumn{2}{|r|}{$H$} & ITY \\
\hline & 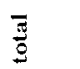 & 它: & 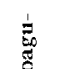 & 象点 & $\begin{array}{l}\Xi \\
=\Xi\end{array}$ & 点 \\
\hline & 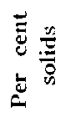 & 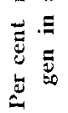 & 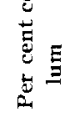 & 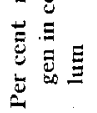 & 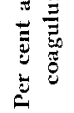 & 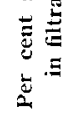 \\
\hline Kansas. & 10.11 & 8.61 & 4.31 & 13.69 & 0.11 & 0.121 \\
\hline So Dakota. & 12.02 & 9.90 & 5.98 & 14.88 & 0.12 & 0.058 \\
\hline Washington. & 11.10 & 8.47 & 6.12 & 12.09 & 0.23 & 0.266 \\
\hline New York.. & 10.50 & 5.14 & 5.18 & 10.42 & 0.39 & 0.244 \\
\hline
\end{tabular}

The degree of purity of the alcohol-soluble based upon the nitrogen content and total solids is approximately less than one-half the purity of pure gliadin of preparing gluten in dry form which when moistened with water takes on all of the characteristics of the gluten from which it was prepared. It occurred to the writer that it might be well to try the above method for the estimation of gliadin on prepared glutens obtained from flours in which the method had been tried directly. Accordingly, one-half gram lots of IoXX bolted gluten from six different flours were digested with two hundred centimeters of 50 per cent alcohol by volume and the method as described above was followed from this point. The per cent of nitrogen in dried gluten, the per cent nitrogen in the alcoholsoluble, the per cent nitrogen in coagulable of the alcohol-soluble, the per cent nitrogen in the phosphotungstic acid precipitated filtrate, the error in the determinations, and the amount of gluten in roo grams of flour from which data the grams of nitrogen in the gluten, the alcohol-soluble and coagulable, have been calculated and are recorded in Table V. The per cent of coagulable nitrogen as found in the alcohol-soluble extract of the flour is introduced in the last column for comparison.

When the possible variations in the results for the determinations of dry gluten, the solubility of gliadin in the process of washing the gluten out of the flour, as well as the possible error involved in making nitrogen determinations, are considered it will be noted (Table $V)$ that the per cent coagulable nitrogen found in alcohol-soluble of the gluten compares remarkably closely with the coagulable nitrogen obtained by the direct extraction of the flour with alcohol. In two instances, viz., B. L. and M. I5, the error is somewhat large, but on closer study it will be further noted that the results obtained in the gluten run lower in all instances

\begin{tabular}{|c|c|c|c|c|c|c|c|c|c|c|}
\hline No. & $\begin{array}{l}\text { Per } \\
\text { cent } N \text { in } \\
\text { gluten }\end{array}$ & $\begin{array}{c}\text { Per } \\
\text { cent } N \\
\text { alcohol- } \\
\text { soluble }\end{array}$ & $\begin{array}{c}\text { Per } \\
\text { cent } N \text { in } \\
\text { coagulable }\end{array}$ & $\begin{array}{l}\text { Per } \\
\text { cent N in } \\
\text { phosphotung- } \\
\text { stic pre- } \\
\text { cipitate }\end{array}$ & Error & $\begin{array}{l}\text { Per cent } \\
\text { gluten } \\
\text { in flour }\end{array}$ & $\begin{array}{c}\text { Per cent } \\
\text { gluten } N \\
\text { in per cent } \\
\text { of flour }\end{array}$ & $\begin{array}{l}\text { Per cent } \\
\text { alcohol- } \\
\text { soluble in } \\
\text { per cent } \\
\text { of flour }\end{array}$ & $\begin{array}{l}\text { Per } \\
\text { cent coagu- } \\
\text { lable } \mathrm{N} \text { in co } \\
\text { per cent } \\
\text { of flour }\end{array}$ & $\begin{array}{c}\text { Per cent } \\
\text { oagulable } \\
\text { found } \\
\text { in flour }\end{array}$ \\
\hline o. C. & 13.66 & 6.64 & 6.32 & 0.46 & +0.12 & 14.20 & 1.95 & 0,94 & 0.90 & 0.96 \\
\hline 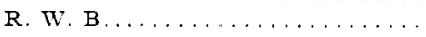 & 13.96 & 8.56 & 5.76 & 2.68 & +0.12 & 9.56 & 1.33 & 0.82 & 0.55 & 0.56 \\
\hline B. I $\ldots \ldots \ldots \ldots \ldots \ldots \ldots$ & 14.38 & 6.64 & 4.96 & 1.60 & -0.08 & 9.35 & 1.34 & 0.56 & 0.46 & 0.58 \\
\hline $\boldsymbol{P} \ldots \ldots \ldots \ldots \ldots \ldots$ & 12.96 & 6.88 & 4.88 & 2.04 & +0.04 & 17.20 & 2.23 & 1.18 & 0.84 & 0.92 \\
\hline L. C $\ldots \ldots \ldots \ldots \ldots \ldots \ldots \ldots$ & 14.24 & 7.52 & 6.56 & 0.96 & 0.00 & 11.60 & 1.65 & 0.87 & 0.76 & 0.69 \\
\hline M. $15 \ldots \ldots \ldots \ldots \ldots \ldots \ldots$ & 14.28 & 6.48 & 4.96 & 1.50 & -0.02 & 12.70 & 1.81 & 0.82 & 0.63 & 0.74 \\
\hline
\end{tabular}

( 7.6 per cent $N$ ) and for the coagulum the nitrogen content (av. I 2.77) agrees with the nitrogen content of giluten ( 2.77 per cent N), ${ }^{1}$ The per cent of sugar found and the per cent of ash are small and seemingly do not influence the purity of the proteins to any great extent. Just how much fat the coagulum carries was not determined, but from determinations made in non-ether extracted preparations of gliadin sometimes as high as 13.5 per cent of ether extract was found and presumably the larger amount of fat in the coagulating method includes fat in the coagulum which fat, if included in gliadin, would reduce the nitrogen per cent in gliadin to figures practically as $10 \mathrm{w}$ as those obtained by the writer for the coagulum.

In research bearing on the properties of gluten and its effect upon the baking qualities of flour, we have been exceedingly fortunate in working out a method

1 ThIS Journal, 4, No. 3 (1912). except one than was the case in the determination in the flour. A possible explanation for the lower results other than those mentioned above may be either that the total alcohol-soluble material contained in the gluten was not entirely extracted or the alcohol-soluble obtained in flour contained other proteins which coagulate with the coagulum and do not combine with the glutenin to form gluten.

At any rate, gluten prepared in the manner described is excellently suited for the preparations of the component proteins of gluten in pure form. The ether-soluble materials can be removed first, then the alcohol-soluble, etc.

It is a recognized fact that gliadin is slightly soluble in water, somewhat in I per cent salt solution and practically insoluble in so per cent salt solution. Accordingly, one would expect to find a part of the gliadin in solution in the filtrates resulting from the 
separation of the coagulum of the alcohol-soluble. In the writer's experience it has been found that the coagulum is difficultly soluble in cold water. Further, upon evaporating the filtrates very small quantities of coagulum result which when transformed into the coagulable state remain practically insoluble. The amount of coagulable material which passes into the filtrates must be exceedingly small and in no case has the writer obtained sufficiently large quantities to warrant a determination to be made. From a quantitative point of view, it is safe to assume that practically all of the gliadin nitrogen has settled out or coagulated and the nitrogen bodies present in the filtrates are of less complex form.

Owing to the difficulties met with in transferring the sticky coagulum formed in the method described above and since the nitrogen contained in the coagulum, together with that found in the filtrate, equal the nitrogen found in the alcohol solution, the writer has deemed it a better method of procedure to estimate the nitrogen in the filtrate resulting from the separation of the coagulum and deduct this result from the nitrogen found in the alcohol-soluble extraction to get the gliadin nitrogen contained in the flour. The method for the estimation of gliadin nitrogen would then read as follows:

Digest four grams of flour with $200 \mathrm{cc}$. of 50 per cent alcohol by volume. Shake the contents at five-minute intervals for the first two hours, then let stand over night and finally fiter clear. Determine the per cent of nitrogen in $25 \mathrm{cc}$. aliquots of the alcohol-soluble. Evaporate slowly $50 \mathrm{cc}$. aliquots of the alcohol-soluble to within $5 \mathrm{cc}$. volume, add $50 \mathrm{cc}$. distilled water, bring near to boil, and continue process until volume has been approximately reduced to ro cc. Repeating, add $50 \mathrm{cc}$. of water and boil down to within $35 \mathrm{cc}$. volume. Allow contents of beakers to cool to room temperature, then filter. If necessary, repeat filter until filtrate becomes practically clear. Estimate the per cent of nitrogen contained in the filtrate and deduct this result from the per cent of alcohol-soluble nitrogen to get the per cent of gliadin nitrogen in the flour.

\section{CONCLUSIONS}

I. Alcohol solutions extract two groups of nitrogen-carrying bodies in wheat flour and gluten. Upon evaporating off the alcohol followed by the addition of water, one of the groups, viz., gliadin, separates out, the other remaining in solution.

II. Salt solution of I per cent strength extracts a part of the gliadin contained in wheat flour.

III. The gliadin nitrogen obtained by the indirect method is much lower than that obtained by the direct method, but agrees remarkably closely with the results obtained for nitrogen in the coagulum in the alcoholsoluble.

IV. Of the two methods for the estimation of gliadin, the coagulation method is the shorter and is more suitable to use for this reason than the indirect method.

$V$. Alcohols ranging between 50 per cent to $6_{5}$ per cent, inclusive, by volume, extract equivalent amounts of coagulum nitrogen. Above $6_{5}$ per cent alcohol by volume there is a rapid falling off in the amount of coagulum nitrogen obtainable. Alcohol of 5o per cent by volume has been adopted by the writer for the determination of gliadin nitrogen.

VI. About 68 per cent of the total alcohol-soluble nitrogen is coagulable.

VII. Alcohol-soluble, incoagulable nitrogen is precipitated by phosphotungstic acid. This, together with the coagulable nitrogen, equals the total alcoholsoluble nitrogen.

VIII. In the same flours as much coagulable nitrogen is obtained in specially prepared gluten as in case of the four.

IX. The easiest and shortest method for the estimation of the gliadin in flour is to estimate the nitrogen in the uncoagulable portion of the alcoholsoluble and deduct this result from the total alcoholsoluble nitrogen.

WASHINGTON EXPERIMENT STATION Pullman

\section{QUALITY OF THE MASSACHUSETTS MILK SUPPLY AS SHOWN BY THE INSPECTION OF THE STATE BOARD OF HEALTH}

By Herman C. Iythgoe

Received August 14, 1913

During the past year an investigation of the milk supply was undertaken with special reference to certain enzyme and other reactions which could possibly differentiate raw milk from pasteurized milk and new milk from old milk. The nature of these reactions and the source of the substances causing them are not yet clearly settled, but a study of the literature shows the following reactions which may be of an enzyme nature:

Raw milk contains a diastase capable of hydrolyzing 0.01 to 0.02 per cent of starch, a catalase which will liberate oxygen from hydrogen dioxide, a peroxidase which will cause hydrogen dioxide to react with certain organic substances, thereby producing colors, and reductases capable of decolorizing methylene blue solutions. Pasteurization has more or less influence upon the above reactions depending upon the temperature of pasteurization and the length of time subjected to this temperature, and the reactions are also modified by the age of the milk.

The reductases are produced by bacteria according to Konning, ${ }^{1}$ Seligman,, ${ }^{2}$ and Grimmer. ${ }^{3}$ On the contrary Seligman ${ }^{2}$ states that some reductase may possibly exist in milk as an enzyme. Romer and Sames ${ }^{4}$ question the enzyme nature of reductase and state that it is produced by the destruction of the cells of the mammary glands during milking, as the first milkings have but slight reducing properties and the last milkings are highly reducing.

Sames ${ }^{5}$ is opposed to the enzyme nature of reductase and thinks that the Seligman assumption that the reduction is due to bacteria is too far reaching. Salus ${ }^{6}$

\footnotetext{
1. Milchwirtschl. Zentr.. 4, 156 .

2 Z. Hyg., 68, 1.

3 Milchwirtschl. Zentr., 6, 243.

* $Z$. Nahr. Genussm., 20, 1

5 Milchwirtschl. Zentr., 6, 462.

A Aph. Hyg., 75, 371 .
} 